\title{
A New Strategy of Transformer Oil Chromatogram Alarm
}

\author{
Qishen Lv \\ Shenzhen Power Supply Bureau Co., Ltd. \\ Shenzhen, China
}

$\mathrm{Mu} \mathrm{Li}$

State Grid Electric Power Research Institute Wuhan NARI Co. Ltd.

Wuhan, China

\author{
Linfa Li \\ Shenzhen Power Supply Bureau Co., Ltd. \\ Shenzhen, China \\ Ronghui Huang \\ Shenzhen Power Supply Bureau Co., Ltd. \\ Shenzhen, China
}

\begin{abstract}
Aiming at the fault early warning of transformer oil chromatographic commonly used the methods in the national standard. In this paper, a method is proposed to obtain alarm thresholds of each component gas within transformer oil chromatogram based on statistical analysis of numerous data. Compared with the value specified in national standard, the threshold obtained there is relatively conservative and can effectively prevent the potential failure from developing. Followed by that, on the basis of determining each gas threshold, through Pearson correlation analysis, a combination alarm strategy with decisionsupporting gas group is proposed. Such method can effectively avoid false alarm due to chromatography measurement error caused by equipment, human and environment factors, so that the alarm accuracy can be improved. The application of the theoretical results in this paper will provide a refined fault early warning method of transformer oil chromatogram to the substation operation and maintenance staffs.
\end{abstract}

Keywords-transformer; oil chromatogram; statistics; threshold; alarm

\section{INTRODUCTION}

Transformer oil will ageing and decompose in normal operation under the influences of thermal, electric, mechanical factors and generate some gas dissolved in the oil. Such gas content will increase abruptly when transformer failure. Therefore, current operation conditions of transformer can be analyzed through monitoring the dissolved gas content in transformer oil. At present, dissolved gas analysis (DGA) of transformer oil is still one of the most effective strategies to monitor the safe and stable operation of oil-immersed transformer[1][3]. It has been almost 30 years of application since 1986 when SD187-86 Guide to the Analysis and the Diagnosis of Gases Dissolved in Transformer Oil was firstly issued.

Oil chromatogram content measurement methods have been updated continuously now, but in the application, transformer oil chromatogram alarm is still based on the caution value of transformer oil dissolved gas content specified in national standard GBT 7252-2001 Guide to the Analysis and the Diagnosis of Gases Dissolved in Transformer Oil, which means to measure current gas concentration and compare it with the caution value specified in the national standard[4]-[5]. When the caution value is exceeded, it is deemed that system dynamic characteristics changes and the transformer might be in abnormal condition and alarm is triggered. However, in practical usage, when alarm is triggered as per the caution value specified in the national standard, equipment has been in failure condition for a while before alarm. For such expensive equipment as transformers, the national standard establishes a relatively broad caution value. Combining theoretical thought of big data, using numerous data samples and analyzing the connotation of these digitals through mathematic statistics, in this paper a method is proposed to determine transformer oil chromatogram alarm threshold and combination alarm strategy for gases. The method will greatly improve the capability of transformer failure alarm and provide guidance to practical engineering application.

\section{STATISTICAL LAW OF CRITERIA}

V.V.Sokolov, a transformer expert of Ukraine ZTZService, believes that, as for the transformer group managed by power company, transformers with possible problems account for no more than $10 \%$, in which the transformers that have more serious problems and require repairing or replacing may account for about $2 \%$. For the remaining $8 \%$, it is required to strengthen the monitoring and to maintain them in advance as cases may be[6]. In fact, many power companies also adopt such an idea, and they pick out a number of transformers with the most serious state of deterioration to maintain and optimize the company's maintenance resources so as to improve the maintenance efficiency of the company.

Based on the above idea, in this paper, the proportion of transformer, less than a certain criteria, to the total number of samples is calculated by collecting the same measured criteria of the same voltage level transformer group in a certain region. After that, a percentage-criteria pair is derived, and the percentage-criteria pair is depicted 
in the two-dimensional coordinate system according to certain rules, and then a curve is fitted. From this curve, the distribution of equipment criteria can be observed. For convenience, this curve is called a reference distribution curve of criteria. Thereafter, through the comparison between the measured criteria and the reference distribution curve of criteria, this criteria can be assessed roughly, and we call this comparison method generalized horizontal comparison. See Figure 1. for the principle.

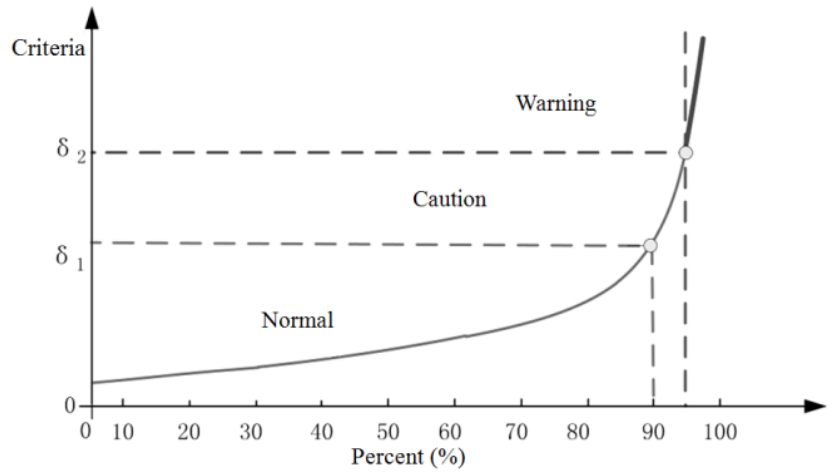

Figure 1. Schematic Diagram of Generalized Horizontal Comparison

$\delta_{1}$ and $\delta_{2}$ in the figure are the thresholds of caution value and warning value respectively, and they can be adjusted reasonably according to user's acceptability to the overall state of current transformer group. And if each gas component in the oil chromatogram adopts a criteria that is less than that corresponding to $90 \%$ (i.e. $\delta_{1}$ value), the equipment is considered normal. If the criteria is within the range $\left(\delta_{1}, \delta_{2}\right]$ corresponding to $90 \%$ to $95 \%$, it is caution, and if the criteria that is more than that corresponding to $95 \%$ (i.e. $\delta_{2}$ value), it is in warning state.

\section{THRESHOLD DETERMINATION OF GAS CONTENT}

\section{A. Probability distribution of gas content}

This paper collets the offline oil chromatographic data of transformers above $110 \mathrm{kV}$ in a certain province in recent years, totaling 15,551 sets. For the analysis of each gas component, this section takes $\mathrm{H} 2$ content of caution value defined in national standard as an example to illustrate threshold determination method and steps of generalized horizontal comparison method.

TABLE I. PREtReAtMent Results OF OIL Chromatogram DATA $\left(\mathrm{H}_{2}\right)$

\begin{tabular}{|c|c|c|c|c|c|c|}
\hline \multirow{2}{*}{$\begin{array}{c}\text { Voltage } \\
\text { Level }\end{array}$} & \multicolumn{2}{|c|}{ Effective } & \multicolumn{2}{c|}{ Missing } & \multicolumn{2}{c|}{ Total } \\
\cline { 2 - 7 } & $\boldsymbol{N}$ & Percent & $\boldsymbol{N}$ & Percent & $\boldsymbol{N}$ & Percent \\
\hline $110 \mathrm{kV}$ & 8275 & $99.0 \%$ & 84 & $1.0 \%$ & 8359 & $100.0 \%$ \\
\hline $220 \mathrm{kV}$ & 6850 & $99.1 \%$ & 62 & $0.9 \%$ & 6912 & $100.0 \%$ \\
\hline $330 \mathrm{kV}$ & 4828 & $99.5 \%$ & 24 & $0.5 \%$ & 4852 & $100.0 \%$ \\
\hline $750 \mathrm{kV}$ & 3780 & $99.8 \%$ & 7 & $0.2 \%$ & 3787 & $100.0 \%$ \\
\hline
\end{tabular}

With regard to $\mathrm{H}_{2}$ content in 15,551 sets of oil chromatogram data, the pretreatment results classified based on the equipment voltage grading are shown in TABLE I.

From the data sheet above, it can be seen that the percent of missing cases in the offline oil chromatogram is less than $1 \%$. Therefore, the method for missing value used in this paper is to remove the missing cases from data set, which will not affect the statistical result. If the proportion of missing cases is larger and the number of samples is insufficient, the following methods can be taken to handle with missing values ${ }^{[7]}$ : (1) mean value substitution, substituting the missing data with the mean value of this average of the variable observed value in other cases; (2) multiple substitution, giving an analog value for each default data from the similar circumstance or based on the distribution of default data derived from observable data later; (3) regression substitution, establishing a regression equation with the observed value of this variable in existing cases and replacing the missing value with conditional expectation value of missing data.

In this paper, $\mathrm{H}_{2}$ at $220 \mathrm{kV}$ voltage level is taken as an example to illustrate the determination method of secondary alarm threshold based on oil chromatographic analysis, and other calculation methods of voltage level are identical. The probability distribution diagram for $\mathrm{H}_{2}$ content at $220 \mathrm{kV}$ after pretreatment is shown in Figure 2. .

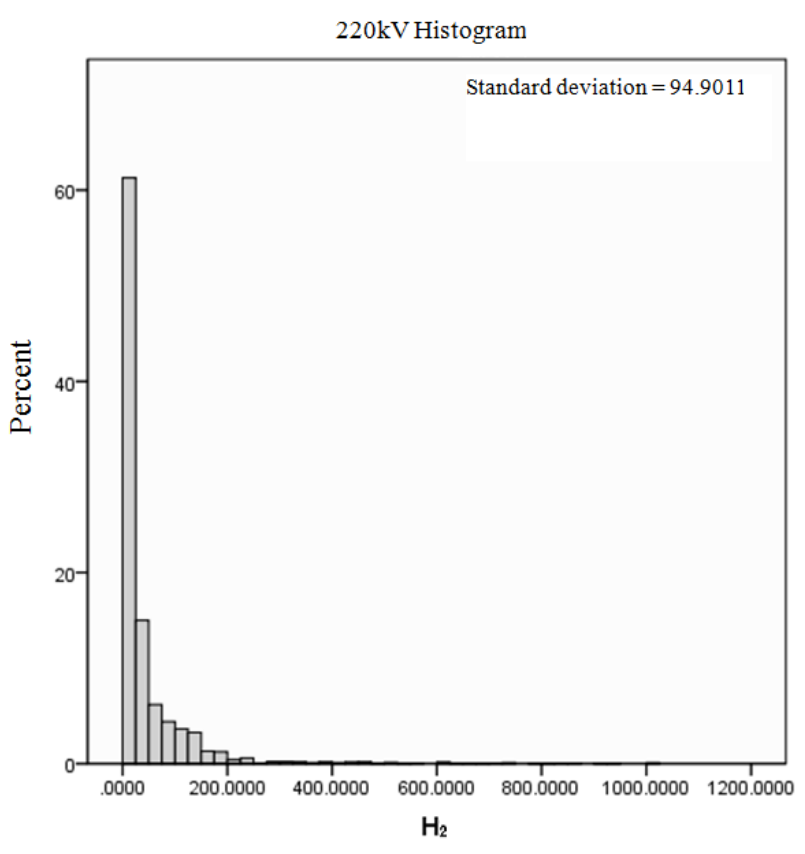

Figure 2. Probability Distribution Histogram for $\mathrm{H}_{2}$ Content at $220 \mathrm{kV}$

\section{B. Hypothesis test and analysis of distribution}

In order to determine whether the probability distribution in Figure 2. is consistent with a certain distribution function, the distribution test is needed. In this paper, P-P probability graph is adopted. The so-called P-P probability graph is drawn based on the relationship between the cumulative proportion of variables and the cumulative proportion of specified distribution ${ }^{[8]}$. When the data is consistent with the specified distribution, points in P-P graph form a straight line approximately. In Figure 3 . , the result derived from the distribution test that is performed with Weibull distribution is given, and the probability density function $f(x)$ and the cumulative distribution function $F(x)$ of Weibull distribution are shown in Equation (1) and Equation (2). Wherein, $k$ is shape parameter and $\lambda$ is scale parameter. 


$$
\begin{gathered}
f(x)=\left\{\begin{array}{l}
\frac{k}{\lambda^{k}} x^{k-1} e^{-(x / \lambda)^{k}}, x \geq 0 \\
0, x<0
\end{array}\right. \\
F(x)=1-\mathrm{e}^{-(x / \lambda)^{k}}
\end{gathered}
$$

As shown in Figure 3., the first graph shows the approach of data points to the straight line $y=x$, and the second graph shows the error fluctuation of data points and $y=x$. From the figure, it can be seen that data points of the first graph are close to $y=x$ and data points of the second graph fluctuate around $y=0$ in a small range, so this verifies the above hypothesis that $\mathrm{H}_{2}$ is consistent with Weibull distribution. TABLE II. gives Weibull distribution parameters of $\mathrm{H}_{2}$ at all voltage levels.
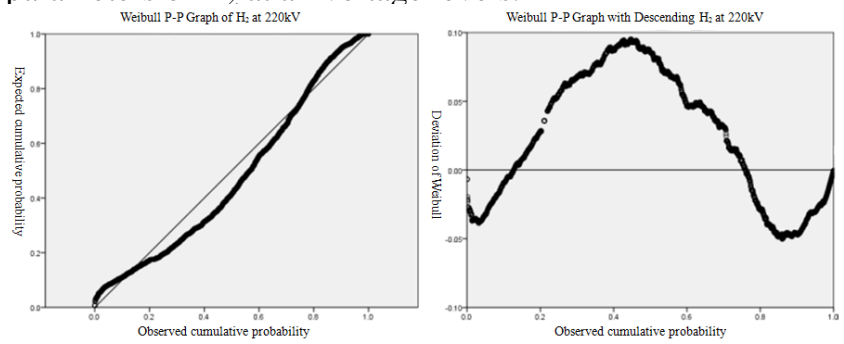

Figure 3. Test Result of Weibull Distribution of $\mathrm{H}_{2}$ at $220 \mathrm{kV}$

TABLE II. WEIBULL DISTRIBUTION PARAMETERS OF $\mathrm{H}_{2}$ AT 220KV

\begin{tabular}{|c|c|c|}
\hline $\begin{array}{c}\text { Weibull } \\
\text { Distribution }\end{array}$ & $\begin{array}{c}\text { Scale Parameter } \\
\boldsymbol{\lambda}\end{array}$ & $\begin{array}{c}\text { Shape Parameter } \\
\boldsymbol{k}\end{array}$ \\
\hline Value & 35.441 & 0.842 \\
\hline
\end{tabular}

After the conversion of formula (2), the following form can be derived:

$$
x=\lambda \times \sqrt[k]{\ln \left(\frac{1}{1-F(x)}\right)}
$$

After substituting $F(x)$ with $90 \%$ and $95 \%$ into Equation (3), the appropriate alarm thresholds $\delta_{1}$ and $\delta_{2}$ can be derived. After substituting Weibull distribution parameter derived from TABLE II. , the secondary alarm threshold determined by a new method can be derived. See TABLE III. for the specific value.

TABLE III. SECONDARY AlaRm THREShOLD OF $\mathrm{H}_{2}$ AT 220KV

\begin{tabular}{|c|c|c|}
\hline Threshold & $\delta_{1} \mathbf{( 9 0 \% )}$ & $\delta_{2} \mathbf{( 9 5 \% )}$ \\
\hline Value & 95.43 & 130.44 \\
\hline
\end{tabular}

\section{Calculation of failure probability}

A major purpose of the threshold defined by national standard (caution value) is to distinguish the normal and failure state of equipment. For example, the threshold of $\mathrm{H}_{2}$ defined by national standard is $150 \mu \mathrm{L} / \mathrm{L}$. When the detected gas concentration is greater than this value, it is confirmed that the equipment is in failure state. If it is less than this value, it is confirmed that the equipment is normal. However, in fact, the equipment is often in normal state when the detected gas concentration is greater than the threshold, and this called false alarm. Or the equipment is in failure state when the gas concentration is less than the threshold, and this is called missing alarm. That is to say, if the gas concentration exceeds the threshold, it does not mean that the equipment is in failure state for $100 \%$, and a more scientific statement is: the failure rate of equipment after the gas concentration exceeds the threshold.

It is supposed that the threshold of gas concentration is $H$, the actual concentration is $X$, the domain of discourse when the equipment is in normal state is $D_{1}$ and the domain of discourse when the equipment is in failure state is $D_{2}$. The failure rate described in this paper is the probability that the equipment is in $D_{2}$ when $X=H$, written as $P\left(D_{2} \mid X\right)$, and statistically:

$$
P\left(D_{2} \mid X\right)=N\left(D_{2}\right) / N
$$

$X \pm 5 \mu \mathrm{L} / \mathrm{L}$ is selected as a select box to select the normal and faulted number of oil chromatogram in 6,912 sets of equipment provided in this paper, and the determination of normal and faulted oil chromatogram is subject to the equipment operation records corresponding to acquisition time of oil chromatogram. $N\left(D_{2}\right)$ means the number of oil chromatogram data under failure state in select box, and $N$ means the total number of oil chromatogram data in select box. See TABLE IV. for the result of failure rate under each threshold.

TABLE IV. FAILURE RATE UNDER EACH THRESHOLD

\begin{tabular}{|c|c|c|c|}
\hline Threshold & $\mathbf{1 5 0} \boldsymbol{\mu} \mathbf{L} / \mathbf{L}$ & $\mathbf{1 3 0} \boldsymbol{\mu} \mathbf{L} / \mathbf{L}$ & $\mathbf{9 5} \boldsymbol{\mu L} / \mathbf{L}$ \\
\hline$N\left(D_{2}\right)$ & 10 & 19 & 28 \\
\hline$N$ & 10 & 22 & 41 \\
\hline$P\left(D_{2} \mid X\right)$ & $100 \%$ & $86 \%$ & $68 \%$ \\
\hline
\end{tabular}

From the sample data analysis, it can be seen that the threshold defined by national standard is too extensive, that is to say, it is almost certain that the equipment is faulted when $\mathrm{H} 2$ content in oil chromatogram is more than $150 \mu \mathrm{L} / \mathrm{L}$, and this setting is not in favor of advance alarm of failure equipment. On the contrary, two threshold settings derived from the method in this paper are relatively conservative, and they can remind maintenance staff to pay more active attention to more equipment to avoid the development of latent failures. They are more suitable for field practice.

\section{COMBINATION AlaRm OF OIL CHROMATOGRAM}

As the decomposition of transformer oil is the products of electrochemistry, there exists mutual connection among certain gas contents. Meanwhile, due to the influences of manufacturing techniques and service life of parts such as oil and gas separating device, chromatographic column and detection sensor in oil chromatogram measuring device, as well as the combined action of external environment factors, it is inevitably to cause error of measurement data. In order to avoid the false alarm caused by measurement error, a method of combination alarm by applying gas contents is proposed exploringly in this paper.

The indicator reflecting the close relation between two variables is considered as correlation coefficient. The common correlation coefficients mainly are Pearson simple correlation coefficient, Spearman rank correlation coefficient and Kendall $\tau$ correlation coefficient ${ }^{[9]}$. This paper adopts Pearson simple correlation coefficient to 
calculate the correlation, which is indicated as $r$. And the corresponding computational formula is as follows:

$$
r=\frac{\sum_{i=1}^{n}\left(x_{i}-\bar{x}\right)\left(y_{i}-\bar{y}\right)}{\sqrt{\sum_{i=1}^{n}\left(x_{i}-\bar{x}\right)^{2}\left(y_{i}-\bar{y}\right)^{2}}}
$$

Wherein, $x$ and $y$ represent two variables respectively. Calculate the correlation coefficients between each two types of 7 types of gas contents for oil chromatogram. And See TABLE V. for the calculation results obtained.

TABle V. CAlculation Results of PeARson CORRElation COEFFICIENTS

\begin{tabular}{|c|c|c|c|c|c|c|c|c|}
\hline \multicolumn{2}{|c|}{ Correlation } & $\mathrm{CH}_{4}$ & $\mathrm{C}_{2} \mathbf{H}_{6}$ & $\mathrm{C}_{2} \mathrm{H}_{4}$ & $\mathrm{C}_{2} \mathrm{H}_{2}$ & $\mathbf{H}_{2}$ & $\mathrm{CO}$ & $\mathrm{CO}_{2}$ \\
\hline \multirow[t]{2}{*}{$\mathrm{CH}_{4}$} & $\begin{array}{l}\text { Pearson } \\
\text { correlation }\end{array}$ & 1 & .560 & .497 & .096 & .128 & .242 & .500 \\
\hline & \begin{tabular}{|l|}
$\begin{array}{l}\text { Significance } \\
\text { (bilateral) }\end{array}$ \\
\end{tabular} & & .000 & .000 & .000 & .000 & .000 & .000 \\
\hline \multirow[t]{2}{*}{$\mathrm{C}_{2} \mathrm{H}_{6}$} & $\begin{array}{l}\text { Pearson } \\
\text { correlation }\end{array}$ & .560 & 1 & .326 & .024 & .067 & .116 & .292 \\
\hline & \begin{tabular}{|l|} 
Significance \\
(bilateral)
\end{tabular} & .000 & & .000 & .084 & .000 & .000 & .000 \\
\hline \multirow[t]{2}{*}{$\mathrm{C}_{2} \mathrm{H}_{4}$} & $\begin{array}{l}\text { Pearson } \\
\text { correlation }\end{array}$ & .497 & .326 & 1 & .103 & .012 & .165 & .596 \\
\hline & $\begin{array}{l}\text { Significance } \\
\text { (bilateral) }\end{array}$ & .000 & .000 & & .000 & .385 & .000 & .000 \\
\hline \multirow[t]{2}{*}{$\mathrm{C}_{2} \mathrm{H}_{2}$} & \begin{tabular}{|l|} 
Pearson \\
correlation
\end{tabular} & .096 & .024 & .103 & 1 & .049 & .002 & .012 \\
\hline & $\begin{array}{l}\text { Significance } \\
\text { (bilateral) }\end{array}$ & .000 & .084 & .000 & & .000 & .863 & .404 \\
\hline \multirow[t]{2}{*}{$\mathrm{H}_{2}$} & \begin{tabular}{|l|} 
Pearson \\
correlation
\end{tabular} & .128 & .067 & .012 & .049 & 1 & .033 & .022 \\
\hline & $\begin{array}{l}\text { Significance } \\
\text { (bilateral) }\end{array}$ & .000 & .000 & .385 & .000 & & .015 & .103 \\
\hline \multirow[t]{2}{*}{$\mathrm{CO}$} & $\begin{array}{l}\text { Pearson } \\
\text { correlation } \\
\end{array}$ & .242 & .116 & .165 & .002 & .033 & 1 & .288 \\
\hline & \begin{tabular}{|l|} 
Significance \\
(bilateral)
\end{tabular} & .000 & .000 & .000 & .863 & .015 & & .000 \\
\hline \multirow[t]{2}{*}{$\mathrm{CO}_{2}$} & $\begin{array}{l}\text { Pearson } \\
\text { correlation }\end{array}$ & .500 & .292 & .596 & .012 & .022 & .288 & l \\
\hline & \begin{tabular}{|l} 
Significance \\
(bilateral)
\end{tabular} & .000 & .000 & .000 & .404 & .103 & .000 & \\
\hline
\end{tabular}

The Pearson correlation in TABLE V. is the correlation coefficient $r$. When $r=0$, it means that there is no linear correlation, but it does not mean that there is no relation between them; when $0<|r| \leq 0.3$, it indicates weak correlation; when $0.3<|r| \leq 0.5$, it indicates low correlation; when $0.5<|r| \leq 0.8$, it indicates significant correlation; and when $|r|=1$, it indicates completely linear correlation. The significance (bilateral) means the testing statistics of Pearson correlation coefficients.

This paper affirmed that when $r>0.5$ between two gas contents, namely these two gas contents are in significant correlation, such gas contents may be used to trigger combination alarm. We can see from the $\mathrm{CH}_{4}$ gas in the first line of TABLE V. that, $\mathrm{C}_{2} \mathrm{H}_{6}, \mathrm{C}_{2} \mathrm{H}_{4}$ and $\mathrm{CO}_{2}$ are in significant correlation with $\mathrm{CH}_{4}$; therefore, $\left[\mathrm{C}_{2} \mathrm{H}_{6}, \mathrm{C}_{2} \mathrm{H}_{4}\right.$, $\mathrm{CO}_{2}$ ] may be set as the decision-supporting gas group of $\mathrm{CH}_{4}$. Under the condition of conservative threshold setting in this paper, in order to reduce the false alarm rate, when there is superthreshold alarm by applying $\mathrm{CH}_{4}$, we may consider the superthreshold alarm of $\mathrm{CH}_{4}$ is effective only on the premise that the gas components of $\left[\mathrm{C}_{2} \mathrm{H}_{6}, \mathrm{C}_{2} \mathrm{H}_{4}\right.$, $\mathrm{CO}_{2}$ ] are all close to alarm threshold $(80 \%)$ or beyond the threshold. When the correlation coefficients of $\mathrm{C}_{2} \mathrm{H}_{2}$ in the fourth line with any other gases are no larger than 0.5 , it may be separately used as alarm gas. However, we can also see from the correlation coefficient 0.103 between it and $\mathrm{C}_{2} \mathrm{H}_{4}$ that, there is weak correlation between them, which is qualitatively similar with the fact that when $\mathrm{C}_{2} \mathrm{H}_{2}$ is detected, there is a small quantity of $\mathrm{C}_{2} \mathrm{H}_{4}$. The selection of auxiliary decision-supporting gas group for other gases can be obtained with such method.

It is clear that the application of combination alarm can effectively avoid the false alarm due to chromatography measurement error caused by equipment, human and environment factors ${ }^{[10]}$, and improve the alarm accuracy to some extent.

\section{CONCLUSIONS}

In this paper, by adopting the theories and analysis thoughts of big data, based on large amounts of oil chromatogram data collected, the determination method of dissolved gas alarm threshold in transformer oil is proposed innovatively and then a combination alarm strategy is also proposed on this basis. Through theoretical analysis and data trial, it is proven that the method can improve the missing and false alarm rates of equipment and is of relatively strong engineering practicality.

\section{REFERENCES}

[1] Li Wenzheng, Li Bin and Li Xiuzhang, "Transformer Failure Judgment and Treatment Based on Oil chromatogram Analysis,' Transformer, vol. 46, 2009, pp. 74-75.

[2] Gong Xuebin, Yan Mingfa and Wei Jingxia, "An Example of Oil chromatogram Analysis Diagnosis and Treatment of Failure within Transformers," High Voltage Apparatus, vol. 44, 2008, pp. 275 276

[3] Li Lei, "Oil chromatogram Analysis and Failure Diagnosis of Transformers," Electrical Manufacturing, 2012, vol. 05, pp. 29-30, 33.

[4] Wang Zhenhua, Lu Qi and Dong Yueqian, "Transformer Station Oil chromatogram Online Alarm and Aided Diagnosis System based on PIs," Zhejiang Electric Power, vol. 31, 2012, pp. 74-76, 84.

[5] Tian He and Chen Xiaohua, "Analysis and Treatment of Exceeding of Main Transformer Oil chromatogram," Transformer, vol. 40, 2003, pp. 44-45.

[6] Victor Sokolov, Armando Bassetto and Jose Mak, "Transformer Risk Assessment Consideration," Proceedings of the Euro TechCon 2002 Conference in UK Bimingham, 2002.

[7] Mao Qunxia, "Simulation Comparison Research and Application of Missing Value Processing Statistical Method," Sichuan University, 2005.

[8] Zong Xuping and Yao Yulan, "Quick Testing the Statistical Distribution of Data through Q-Q and P-P Figures," Statistics and Decision, vol. 20, 2010, pp. 151-152.

[9] Zhou Zhinian and Peng Xiaojuan, "Excel Realization of Related Analysis of Pearson, Spearman and Kendall's Tau," Journal of Clinical and Experimental Medicine, vol. 11, 2012, pp. 461-463.

[10] Ma Guopeng, He Yunliang and Huang Fengpu, "False Alarm Cause Analysis of Transformer Oil chromatogram Online Monitoring Device," Electric Safety Technology, vol. 12, 2013, pp. 8-10. 